\title{
Structural MRI studies of language function in the undamaged brain
}

\author{
Fiona M. Richardson · Cathy J. Price
}

Received: 29 January 2009/Accepted: 29 June 2009/Published online: 18 July 2009

(C) The Author(s) 2009. This article is published with open access at Springerlink.com

\begin{abstract}
In recent years, the demonstration that structural changes can occur in the human brain beyond those associated with development, ageing and neuropathology has revealed a new approach to studying the neural basis of behaviour. In this review paper, we focus on structural imaging studies of language that have utilised behavioural measures in order to investigate the neural correlates of language skills in the undamaged brain. We report studies that have used two different techniques: voxel-based morphometry of whole brain grey or white matter images and diffusion tensor imaging. At present, there are relatively few structural imaging studies of language. We group them into those that investigated (1) the perception of novel speech sounds, (2) the links between speech sounds and their meaning, (3) speech production, and (4) reading. We highlight the validity of the findings by comparing the results to those from functional imaging studies. Finally, we conclude by summarising the novel contribution of these studies to date and potential directions for future research.
\end{abstract}

Keywords Language $\cdot$ Brain structure $\cdot$ Grey matter . White matter $\cdot$ VBM $\cdot$ DTI

\section{Abbreviations \\ VBM Voxel-based morphometry \\ DTI Diffusion tensor imaging}

F. M. Richardson $(\varangle) \cdot$ C. J. Price

Wellcome Trust Centre for Neuroimaging,

University College London, 12 Queen Square,

London WC1N 3BG, UK

e-mail: fiona.richardson@ucl.ac.uk

\section{Introduction}

The relationship between brain structure and language function is important for understanding typical and atypical language development and the consequences of brain damage. An exciting recent development is the discovery that local experience-dependent changes in structure can take place in the adult brain, overturning the previously held view that structural change is limited to critical or sensitive periods in early life (Lenneberg 1967; Johnson 2005). Several studies have now identified regional differences/changes in morphological structure (grey matter and white matter) associated with the acquisition of knowledge or skills in adulthood (Draganski et al. 2004; Gaser and Schlaug 2003; Golestani et al. 2002; Maguire et al. 2000; Mechelli et al. 2004) and subsequently across lifespan, from childhood to old age (Lee et al. 2007; Boyke et al. 2008; Richardson et al. 2009). Furthermore, longitudinal studies have provided evidence with some conviction that these differences are not only behaviourally correlated but can also occur as a consequence of skill acquisition, and are then maintained only for as long as the skill is practised (Draganski et al. 2004; Boyke et al. 2008). These exciting new developments mark the emergence of a new perspective in the study of the neural basis of behaviour.

An interesting feature of these studies is that the locations of the structural differences frequently correspond to regions that are also functionally active during tasks that engage these skills. For instance, increased grey matter in the posterior hippocampi of taxi drivers (Maguire et al. 2000) is consistent with functional imaging data showing bilateral activation of the hippocampi during navigational tasks (Maguire et al. 1998). These data support the view that the observed structural differences are indeed related 
to navigational ability. Recent imaging studies have sought to establish a more direct link between local structure and functional activation. For instance, in a study by Ilg et al. (2008), participants were trained to become proficient at mirror reading. Changes in grey matter associated with the acquisition of this skill were located in the right dorsolateral occipital cortex which also showed an activation peak from a functional imaging mirror-reading task. This study illustrates that increased proficiency in a specific skill can bring about structural changes that correspond to taskspecific activation, affirming a close relationship between structure and function.

Structural imaging studies typically involve the regional comparison of brain structure across two groups of participants (e.g., trained vs. untrained) or the correlation of local brain structure with language abilities. Both approaches help to localise brain regions that support language function. Ultimately, a more precise understanding of the structures that support various language skills (e.g., verbal fluency, reading, and comprehension) could prove useful in predicting deficits on the basis of lesion location(s).

In this paper, we provide a comprehensive review of studies published to date which used structural MRI to study language skills in the undamaged brain. At present, there are a limited set of studies illustrating the potential of this technique. Consequently, there are currently insufficient studies with a common theme to provide an integrated review of the language system or to contribute a new theoretical perspective. The structure of the review therefore takes the following form. We begin with a brief introduction to the techniques that have been used. We then provide an overview of studies that have investigated (1) the perception of novel speech sounds, (2) the links between speech sounds and their meaning, (3) speech production, and (4) reading. In each section the value of these studies is illustrated by comparing the findings to those from functional imaging studies of the corresponding skills, highlighting similarities as well as novel insights. Finally, we conclude by summarising the contribution of structural imaging studies to date, their theoretical implications, and potential directions for future research.

\section{Structural MRI techniques for studying language function}

The most prominent techniques used in structural MRI studies of language in the undamaged brain are voxelbased morphometry (VBM, Ashburner and Friston 2000) and diffusion tensor imaging (DTI, Le Bihan et al. 2001). Both can correlate or compare brain structure (grey/white matter) with a behavioural language measure. As its name implies, VBM is conducted on a voxel-by-voxel basis across the whole brain and therefore offers relatively high spatial resolution. DTI traces white matter pathways (i.e. tractography) in the living human brain and has proved to be particularly useful in clinical neuroscience: for example, in tracking the progression of degenerative diseases and adaptive reorganisation following brain damage (Ciccarelli et al. 2008). Below, we provide a brief overview of these methods as applied to structural studies of language skills.

VBM is a statistical technique for identifying local morphological differences in the concentration of grey or white matter in structural MR images (Ashburner and Friston 2000; Mechelli et al. 2005). These differences may be detected by comparing two groups of participants, such as a control and a patient group, and/or by correlating differences in grey or white matter with a behavioural performance measure (such as number of words spelled correctly). VBM entails a mass-univariate voxel-by-voxel analysis of the whole brain, and in this sense is an unbiased and objective technique for analysing structural images that does not rely on a priori regions of interest or the manual parcellation of cortical regions. A further advantage of VBM is that it is able to provide an accurate localisation of any detected differences (as opposed to characterising these in terms of broadly-defined regions), making it possible to link findings more closely to functional imaging data. However, it is important to note that VBM does not identify the causes of the observed structural changes at the micro-level. For instance, an increase in grey matter could represent a region of increased cortical folding or a thicker area of cortex.

The second technique used by the studies reported in this review is diffusion tensor imaging (DTI), which tracks white matter pathways in the brain by using the principles of water diffusion. As water molecules diffuse along a path of least resistance, they travel parallel to white matter fibres. This results in a different MRI signal depending on the direction of diffusion. This measurement of anisotropy indicates the preferential diffusion direction which can be used to infer an indirect tract of white matter pathways (see Le Bihan et al. 2001 and Hagmann et al. 2006 for an overview of DTI). Fractional anisotropy (FA) expresses the degree of anisotropy, and these values can then be correlated with behavioural measures, e.g. test scores on language tasks. For example, Catani et al. (2007) showed that the extent to which the arcuate fasciculus (connecting Broca's and Wernicke's areas) is left lateralised is inversely correlated with performance on the Californian Verbal Learning Task (Catani et al. 2007). Thus, those with more symmetrical white matter in the arcuate fasciculus were better able to remember lists of semantically related words.

DTI is the only method available for tracing white matter pathways (i.e. tractography) in the living human brain. The limitation of this method, however, is that it 
cannot be used to determine whether a pathway is functional, or to distinguish between anterograde and retrograde connections. DTI also struggles in regions where fibre tracts cross or run close to grey matter as anisotropy is very low in these areas.

In the sections that follow, we review studies that have utilised these methods to investigate the relationship between language skills and structure in the undamaged brain. The limited number of studies to date makes it impossible to provide a systematic review which could test or develop a theoretically motivated cognitive model of language. Nevertheless, we have grouped the discussion of these studies into the types of language processes that they tap. The first section focuses on structural imaging studies of speech perception, the second on the link between the sounds of words and their meaning, the third on speech production and the fourth on reading. Each section highlights the potential of the structural imaging approach by comparing the results to those from functional imaging and lesion studies.

\section{The perception of novel speech sounds}

Golestani and colleagues have conducted two structural neuroimaging studies investigating the ability to distinguish novel speech sounds (Golestani et al. 2002, 2007). In the first of these studies, 59 native English-speaking adults were trained to perceive the difference between two novel phonemic contrasts-the dental and retroflexive speech sounds used in Hindi (Golestani et al. 2002). The speed at which each participant learnt to identify these different speech sounds was recorded across training sessions, and used to calculate their rate of learning. Golestani et al. 2002 found that this learning rate was positively correlated with white matter density bilaterally in a region anterior to the parietal-occipital sulcus, indicating that those who learnt to distinguish between speech sounds more quickly had more white matter in this region. A morphometric analysis of the parietal-occipital sulcus also showed that this sulcus was located more posteriorly in faster learners. Golestani et al. 2002 suggest that more parietal white matter in faster learners may be due to increased myelination which allows faster and more efficient processing of complex temporal acoustic signals such as speech.

Interestingly, these effects of phonemic learning on brain structure can be linked to a functional MRI study by the same authors (Golestani and Zatorre 2004) in which they correlated phonemic learning rate on the same task with functional activation in native English-speaking adults. The results indicated that the degree of success in phonemic learning is accompanied by more activation in left temporo-parietal speech areas and less activation in frontal speech regions. As summarised in Table 1, the proximity of the white matter and activation changes (in the structural and functional imaging studies, respectively) suggests that the effects arise from the same processing network. Specifically, Golestani and Zatorre (2009) have suggested that these parietal effects may reflect the formation of a long-term memory category representation for new speech sounds.

In their second structural imaging study, Golestani et al. (2007) repeated the same experiment in 65 native Frenchspeaking adolescents and adults, all of whom had a similar experience of language learning (having knowledge of, but not being proficient in, two additional languages). As in their first experiment, the participants were trained to perceive the difference between two novel phonemic contrasts (the dental and retroflexive speech sounds used in Hindi). The results replicated the findings from the first study with English-speaking participants, but also highlighted two novel observations across both groups of participants. It was found that those who were quicker to learn showed a greater leftward asymmetry in the parietal lobes and also had more white matter in left Heschl's gyrus (which lies in the heart of the primary auditory cortex). The latter finding is in accord with other studies that found increased grey matter in the auditory cortex in those with good auditory perception. For instance, structural and functional differences in Heschl's gyrus have been observed in musicians (Gaser and Schlaug 2003; Schneider et al. 2002) as well as for those with an aptitude for learning tonal languages such as Mandarin, where pitch is particularly important for distinguishing between words (Wong et al. 2008). Together these studies show consistent effects of brain structure in the parietal and auditory

Table 1 Parietal correlations with phonemic learning rate

\begin{tabular}{|c|c|c|c|c|c|c|c|}
\hline \multicolumn{4}{|l|}{$\begin{array}{l}\text { Structural, white matter } \\
\text { Golestani et al. (2002) }\end{array}$} & \multicolumn{4}{|c|}{$\begin{array}{l}\text { Functional } \\
\text { Golestani and Zatorre (2004) }\end{array}$} \\
\hline Location & $x$ & $y$ & $z$ & Location & $x$ & $y$ & $z$ \\
\hline Anterior to right parieto-occipital sulcus & 17 & -50 & 23 & Right angular gyrus & 44 & -70 & 34 \\
\hline Anterior to left parieto-occipital sulcus & -16 & -64 & 38 & Left angular gyrus & -54 & -66 & 26 \\
\hline
\end{tabular}

The co-ordinates in this table are in Talairach space as reported in the original studies 
cortices that validate the results of Golestani and colleagues and the use of VBM, illustrating that structural imaging has the potential to provide new insights that will increase our understanding of the functional anatomy of language. For example, the studies carried out by Golestani and colleagues suggest that the ability to learn novel speech sounds may in part be influenced by the structural properties of the auditory cortex and the inferior parietal lobe.

\section{Linking speech sounds to meaning}

In the previous paragraphs, we considered studies concerned with the ability to learn novel speech sounds. We now turn to the ability to link speech sounds with their meanings. This is not a unitary process and has not been thoroughly investigated to date. There are however, three studies in the neurologically normal brain that have highlighted brain regions where the structure appears to reflect the number of words in a person's vocabulary. The first of these studies compared the brains of bilinguals to monolinguals (Mechelli et al. 2004). Although it could be argued that the brains of these two groups might differ in several ways other than in word knowledge, two subsequent studies of vocabulary knowledge in monolingual participants found that the brain areas associated with bilingualism were also associated with the number of words learnt (Lee et al. 2007; Richardson et al. 2009). We discuss each of these three studies in turn.

The comparison of brain structure in bilinguals and monolinguals involved 25 English monolinguals, 25 early bilinguals who had acquired their second language before the age of 5 years, and 33 late bilinguals who had acquired their second language between the ages of 10 and 15 years, but had practiced their second language regularly for at least 5 years. Mechelli et al. (2004) found that bilinguals had a greater grey matter density in comparison to monolinguals in a region of the left inferior parietal cortex that was localised in the posterior supramarginal gyrus. This was a surprising result because functional imaging studies of language do not typically activate this area, which lies between areas associated with phonological processing in the anterior supramarginal gyrus and semantic processing in the angular gyrus. Nevertheless, the importance of the posterior supramarginal gyrus for bilingualism was confirmed in a follow-up study also reported in Mechelli et al. (2004) using a separate group of 22 Italian-English bilinguals who had learnt their second language between the ages of 2 and 34 years. In this second sample of subjects, brain structure was correlated with second language proficiency (over a range of reading, writing, speech comprehension and production tasks) and demonstrated that grey matter density in the posterior supramarginal gyrus was positively correlated with second language proficiency and negatively correlated with age of second language acquisition. In other words, posterior supramarginal grey matter was highest in those who were most proficient in their second language. These people also tended to be those who had acquired a second language at an early age.

The potential importance of the posterior supramarginal gyrus in language processing was subsequently investigated in a structural imaging study of vocabulary knowledge in 32 monolingual teenagers by Lee et al. (2007). They found that posterior supramarginal grey matter density was positively correlated with vocabulary knowledge and suggested that grey matter in this region might be a neural marker for the number of words learnt. In considering the potential role of the posterior supramarginal gyrus in the acquisition of vocabulary knowledge, Lee et al. (2007) examined the anatomical position of this region which, as we mention above, lies between the anterior supramarginal gyrus associated with phonological processing and the angular gyrus associated with semantic processing (Démonet et al. 1992; Devlin et al. 2003; Price et al. 1997). The anatomical location of the posterior supramarginal gyrus therefore suggests that it may play a role in linking phonological and semantic word information. Lee et al. (2007) investigated this hypothesis using DTI to examine the white matter tractography in this region. They identified direct anatomical connections between the posterior and anterior supramarginal gyrus and also between the posterior supramarginal gyrus and the angular gyrus, but they found no direct links between the anterior supramarginal gyrus and the angular gyrus. This evidence supports the hypothesis that the posterior supramarginal gyrus may be a binding site for phonological and semantic information, a process central to vocabulary acquisition in both a first and a second language.

In the third paper (Richardson et al. 2009) the relationship between vocabulary knowledge and brain structure was investigated in a sample of 47 participants who ranged in age from 7 to 75 years. Unlike Lee et al. (2007) who assessed vocabulary knowledge using verbal descriptions, the task in Richardson et al. (2009) involved pointing to the picture that best described the word. Despite the change in task, the relationship between vocabulary knowledge and posterior supramarginal grey matter was replicated in the teenage participants $(n=16)$. The close correspondence between the peak co-ordinates from the Richardson et al., Lee et al., and Mechelli et al. studies is illustrated in Fig. 1.

In addition to replicating the findings reported in Lee et al. (2007), the Richardson et al. (2009) study identified two novel findings. The first was that the relationship between vocabulary knowledge and grey matter density in the posterior supramarginal gyrus was specific to the teenage years. It was demonstrated that this finding was not 


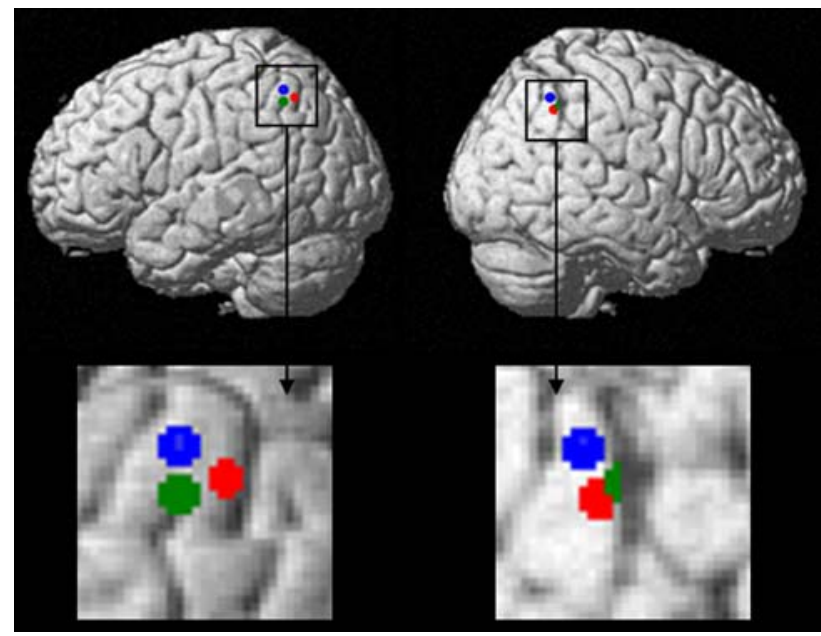

Fig. 1 Structural variance with vocabulary knowledge in the posterior supramarginal gyrus. Locations of the peak co-ordinates from the following studies: red Mechelli et al. (2004), blue Lee et al. (2007), and green Richardson et al. (2009). (For figure co-ordinates see Table 3 in Appendix)

a consequence of a lack of sensitivity because two other left temporal and parietal regions were identified where grey matter was positively correlated with vocabulary knowledge across lifespan. These other regions were located deep in the left posterior superior temporal sulcus and in the left posterior temporo-parietal cortex. In both regions vocabulary knowledge was positively correlated with structural MR images and functional activation images acquired during an auditory and visual sentence processing task. Thus, Richardson et al's. study demonstrates a close link between local differences in brain structure and functional activation in left temporal and parietal regions and suggests that an increase in grey matter correlates with an increase in functional activation (as shown in Fig. 2).

In summary, by comparing structural and functional correlations with vocabulary across lifespan, Richardson et al. (2009) observed two distinct effects. In the left posterior temporal regions, grey matter was correlated with vocabulary across the lifespan trajectory but, by contrast, grey matter in the posterior supramarginal gyrus was only
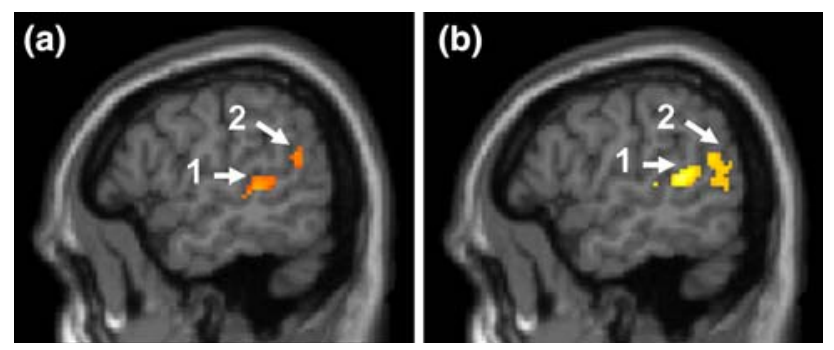

Fig. 2 a Structural and b functional variance with vocabulary knowledge in (1) the left posterior superior temporal sulcus, and (2) a left posterior temporo-parietal region. Adapted from Richardson et al. (2009) correlated with vocabulary knowledge in the teenage years. Richardson et al. (2009) interpret this regional dissociation in terms of two different learning strategies for acquiring vocabulary knowledge. They suggest that continuous changes across lifespan may represent vocabulary learning that occurs through exposure to everyday language via semantic and syntactic associations and prior knowledge of morphological structure (see Kilian et al. 1995; and Nagy et al. 1985). In contrast, the correlation of vocabulary knowledge with grey matter in the left posterior supramarginal gyrus in teenage years, but not later in life, suggests that this region may be engaged in a mode of learning more typically exploited within formal education, e.g. learning to link new words with specific lexical equivalents. This may also explain why activation of the posterior supramarginal gyrus is only usually found in language tasks that involve explicit word learning (Cornelissen et al. 2004).

Overall, the three studies reported above have highlighted the importance of a new language region. This region, located in the posterior supramarginal gyrus, is not typically reported in functional imaging studies of language but may play an important role in both first and second language learning. Future work using longitudinal studies is now required to establish whether grey matter changes can be measured within subject during the process of learning new words.

\section{Speech production}

To our knowledge there are only two structural imaging studies of the undamaged brain that have investigated the brain regions that support speech production. The first was by Golestani and Pallier (2007) who trained 21 French-speaking participants to produce a non-native Farsi consonant (a voiced uvular stop) which could be clearly distinguished from their native speech sounds. Those who had more accurate pronunciations had higher white matter density in the left insula/ prefrontal cortex and bilaterally in the inferior parietal lobes. The effects in the left insula/prefrontal cortex are particularly interesting given the known role of these regions in planning articulatory output, as suggested by functional activation studies of phonological working memory (Chee et al. 2004) and lesion studies of aphasic patients (Dronkers et al. 1999). Therefore, yet again, the results of the structural imaging analyses are concordant with what is expected from other techniques.

The second structural imaging study of speech production in the undamaged brain is reported by Grogan et al. (2009). Unlike the Golestani and Pallier (2007) study, the task involved the production of familiar words from memory in response to phonemic or semantic cues. The participants were 59 adults who were proficient speakers of 
two or more languages and they were tested in their ability to produce words in their first and second language.

The phonemic fluency task involved the production of words beginning with a specific letter (e.g. "t"), while the semantic fluency task involved the production of words from a given category (animals or fruit and vegetables). The results identified a positive correlation with overall fluency in the cerebellum (lobes VIIB and VIIIA), significant at the whole brain level. This finding is consistent with functional imaging studies that support the role of the cerebellum in verbal fluency (see Desmond and Fiez 1998). In addition, there was a double dissociation in the brain regions where grey matter correlated with phonemic relative to semantic fluency. Increased grey matter in the pre-supplementary motor area and in the right and left head of the caudate was associated with better phonemic than semantic fluency. Conversely, bilateral ventral anterior temporal grey matter was more strongly correlated with semantic than phonemic fluency. These structure-behaviour correlations were consistent for first and second languages.

Grogan et al. (2009) validated their findings by showing that the results correspond to those from a functional imaging study of phonemic and semantic fluency that was previously reported by Mummery et al. (1996). Thus, as in the Golestani et al. studies $(2002 ; 2007)$ and Richardson et al. (2009), there was a correspondence between the findings of structural and functional imaging modalities. More importantly, however, the study by Grogan et al. (2009) illustrates how structural imaging can investigate tasks that are difficult to control in functional imaging paradigms: for example, it is very difficult to control the rate of word production during a fluency task.

\section{Reading pathways}

Reading involves to the ability to access the language system from visual rather than auditory stimuli. Cognitive models of reading divide the ability to read into at least three different components: (a) orthographic processing of the visual letter strings, (b) phonological processing that links orthographic input to speech sounds, and (c) semantic processing that links orthographic input to meaning. Depending on the cognitive model, each of these components can be further subdivided. For example, dual route models distinguish between lexical (whole word) and sublexical (word constituents) links between orthography and phonology (Patterson and Shewell 1987; Coltheart et al. 2001). The motivation for this distinction was to explain the normal ability to read both (1) unfamiliar nonwords (e.g. SHAP) that can only be assembled from their sublexical parts, and (2) familiar words with irregular spellings (e.g. CHOIR) that require whole word lexical knowledge because their pronunciations cannot be assembled from their parts. The dissociation between the ability to read nonwords and irregularly spelled words is particularly obvious in acquired dyslexia. For instance, some patients can read nonwords better than irregularly spelled words (e.g. surface dyslexics), while other patients can read irregularly spelled words better than nonwords (e.g. phonological dyslexics). However, some cognitive models of reading propose that this double dissociation does not necessarily imply a dissociation between lexical and sublexical links from orthography to phonology. Instead, it can be accounted for in terms of semantic mediation (Seidenberg and McClelland 1989; Plaut et al. 1996). Thus, when semantic mediation is poor, it will be more difficult to recognise words with irregular spellings, but when phonological processing is poor, it will be more difficult to recognise nonwords that do not have meaning.

Studies of patients with brain damage have clearly indicated that the ability to read can break down in multiple ways (see Patterson and Ralph 1999 for a review). Likewise, there is increasing evidence that the ability to learn to read can be impaired in different ways (e.g. Castles and Coltheart 1993; Cohen et al. 1999; Fabbro et al. 2001; Ho et al. 2007; Manis et al. 1996; Shu et al. 2005; SprengerCharolles et al. 2000; Zabell and Everatt 2002; Ziegler et al. 2008). There is even evidence that skilled readers vary in whether they are relatively better at reading nonwords or irregularly spelled words (Seghier et al. 2008). By comparing the ability to read nonwords and irregularly spelled words, structural and functional imaging studies have the potential to investigate the degree to which different reading pathways are segregated in the brain.

Here, our focus is on the contribution of structural imaging studies. However, to date, there are no studies that have reported a double dissociation in the structural correlates of reading nonwords and irregularly spelled words. Moreover, the majority of structural studies of reading ability have compared brain structure in those who have and have not been diagnosed with developmental dyslexia. By definition, those with developmental dyslexia have difficulties with accurate and/or fluent word recognition, spelling, learning grapheme-to-phoneme correspondences (Stanovich and Siegel 1994) and pronouncing heard nonwords (Lyon et al. 2003), despite an absence of any non-verbal cognitive impairment and normal educational opportunities to learn (Snowling 2000). This disorder is predominantly associated with difficulties in phonological processing, which include poor phonological awareness (ability to access and manipulate speech sounds), slow lexical retrieval, and poor verbal short-term memory (Ramus 2004). Difficulties in phonological processing can continue into adolescence and adulthood (Elbro et al. 1994; Shaywitz et al. 1999).

Nevertheless, developmental dyslexia is not a homogeneous condition and therefore there is great variability in 
how it is expressed in one individual relative to another. There is also variance in the degree to which dyslexics have other non-linguistic difficulties that are not related to reading (Ramus et al. 2003): for example, poor motor skills or difficulties in balance, co-ordination and fine motor skills (Fawcett and Nicolson 1995). As a result, group differences between developmental dyslexics and skilled readers could arise at multiple levels depending on the sample of dyslexics tested (i.e. their age and behavioural profile of linguistic and non-linguistic difficulties), and the measure used to assess the concentration of grey or white matter in a given brain region (i.e. in VBM concentration may be measured as volume or density—see Mechelli et al. 2005 for further details on the difference between these two measures). Indeed, when we summarised the results of nine VBM studies (see Table 2; Fig. 3) which have identified less or more grey matter in group comparisons of developmental dyslexics and good readers, a widely distributed set of regions are reported in both left and right hemispheres. Those most frequently reported include: posterior temporal/temporo-parietal regions (Brambati et al. 2004; Hoeft et al. 2007; Silani et al. 2005; Steinbrink et al. 2008), occipito-temporal regions bilaterally (Eckert et al. 2005; Brambati et al. 2004; Kronbichler et al. 2008), and the cerebellum (Brown et al. 2001; Brambati et al. 2004; Eckert et al. 2005; Kronbichler et al. 2008). In addition, studies of white matter have reported group differences in the left temporo-parietal region (Klingberg et al. 2000; Beaulieu et al. 2005; Deutsch et al. 2005; Silani et al. 2005; Steinbrink et al. 2008) and the temporo-callosal pathway (Dougherty et al. 2007) (Table 5; see Appendix).
The problem with interpreting group differences in the brain structure of developmental dyslexics and good readers is that we cannot establish a causal link: given that brain structure correlates with ability, less grey matter could be the cause or the consequence of poor reading. An alternative approach is to correlate brain structure with performance on a range of different tasks. As mentioned above there are no published studies to date that have compared the ability to read nonwords versus irregularly spelled words. However, there are a few studies that have correlated grey or white matter with either word or nonword reading ability. Thus, faster word reading speed has been associated with more grey matter in the fusiform and cerebellum bilaterally (Kronbichler et al. 2008) and deep in the middle temporal cortex (Silani et al. 2005); while better nonword reading has been associated with greater grey matter volume in the left superior temporal gyrus, bilateral medial frontal and paracentral regions, posterior cingulate and the visual cortex (Pernet et al. 2009). The lack of consistency between these studies is difficult to interpret because there were no direct comparisons of word and nonword reading. However, correlations of reading ability with white matter have been far more consistent across studies (see Fig. 4). For example, measures of left temporo-parietal white matter (e.g. fractional anisotropy) have been positively correlated with faster or more accurate nonword reading (Steinbrink et al. 2008) or word reading (Klingberg et al. 2000; Beaulieu et al. 2005; Deutsch et al. 2005; Niogi and McCandliss 2006). These positive correlations were observed in both good and dyslexic readers, so they are not a hallmark of the dyslexic brain. Instead, they

Table 2 VBM studies of grey matter in dyslexia

\begin{tabular}{|c|c|c|c|}
\hline Study & Sample & Measure & Statistical analysis \\
\hline 1. Brown et al. (2001) & Adults mean age 24 years & Density & $\begin{array}{l}\text { Height threshold } P<0.05 \text {, corrected } P<0.05 \\
\text { for extent }\end{array}$ \\
\hline 2. Brambati et al. (2004) & Family study aged $13-57$ years & Volume & $\begin{array}{l}\text { Small volume correction at } P<0.05 \text {, minimum cluster } \\
\text { size } 25 \text { voxels }\end{array}$ \\
\hline 3. Silani et al. (2005) & Adults mean ages $24-28$ years & Volume & $\begin{array}{l}\text { Small volume correction for regions of interest } 10 \mathrm{~mm} \\
\text { spheres, whole brain } P<0.05 \text { corrected }\end{array}$ \\
\hline 4. Vinckenbosch et al. (2005) & Adults aged $17-30$ years & Density & Corrected $P<0.01$ for height and $P<0.05$ extent \\
\hline 5. Eckert et al. (2005) & Children mean age 11 years & Volume & $\begin{array}{l}P<0.001 \text { uncorrected for ROIs, } P<0.05 \mathrm{FWE} \\
\text { corrected } / P<0.00001 \text { for other regions }\end{array}$ \\
\hline 6. Hoeft et al. (2007) & $\begin{array}{l}\text { Children and adolescents mean } \\
\text { age } 14 \text { years }^{\mathrm{a}}\end{array}$ & Volume & Whole brain corrected at $P=0.01$ for height and extent \\
\hline 7. Kronbichler et al. (2008) & Adolescents mean age 15 years & Volume & $\begin{array}{l}\text { Whole brain } P<0.005 \text { uncorrected and volume of } \\
\text { interest corrected FDR }<0.05\end{array}$ \\
\hline 8. Steinbrink et al. (2008) & Adults mean age 20 years & Volume & Whole brain $P<0.05$ FDR corrected, cluster size $>650$ \\
\hline 9. Pernet et al. (2009) & Adults mean age 27 years & Volume & $\begin{array}{l}\text { Between group maps corrected for multiple } \\
\text { comparisons } P=0.003, \text { FDR correction } q=0.05\end{array}$ \\
\hline
\end{tabular}

a The study by Hoeft et al. (2007) used reading age and chronological age matched controls. Reading age matched controls had a mean chronological age of 9 years 

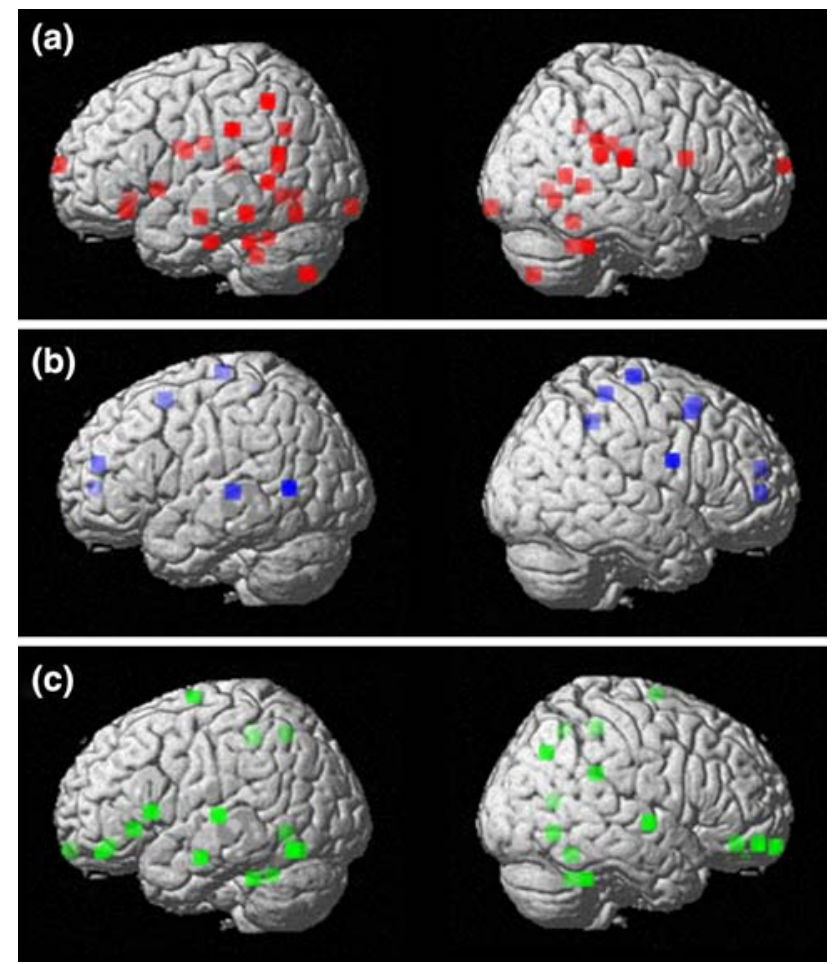

Fig. 3 Differences in grey matter in dyslexia. Locations of the peak co-ordinates in regions with $\mathbf{a}$ less grey matter and $\mathbf{b}$ more grey matter relative to controls, and $\mathbf{c}$ regions that are positively correlated with behavioural performance in language tasks across both controls and dyslexics. This Figure was plotted using peak co-ordinates from the studies listed in Table 1 (for figure co-ordinates see Table 4 in Appendix)

highlight the importance of left temporo-parietal white matter tracts for skilled and efficient reading.

\section{Summary and conclusion}

In summary, the structural imaging studies we have reviewed demonstrate some key points regarding the relationship between local brain structure and task performance in the undamaged brain. First, higher scores on cognitive tests generally reflect a greater concentration of the neural substrates being measured. Second, the anatomical location of these correlations between behaviour and brain structure are frequently linked to and correspond with areas showing correlations between behaviour and functional activation. Nevertheless, structural imaging studies are also offering novel conclusions that have not previously been possible with functional imaging studies. For example, it is noteworthy how often grey and white matter in the inferior parietal lobes has been associated with language learning. In particular, the posterior supramarginal gyrus is particularly surprising because this region is not usually found in functional imaging studies of language.
Novel insights from structural imaging are important, not only in terms of understanding the neural basis of linguistic skills in the undamaged brain, but also in the context of atypical system disorders. Firstly, in reference to developmental disorders of language, identifying regions that deviate from typical structural properties may in future provide a more accurate basis for diagnosis and effective remediation. Moreover, investigating the pattern of these structural differences over time in relation to improvements in linguistic skills may provide an insight into brain regions supporting the process of compensation, which in turn may also influence remediation strategies and identify the most appropriate period for intervention. Secondly, in consideration of acquired disorders of speech perception and production, the identification of critical regions offers the opportunity for a predictive model of language deficits.

The studies reviewed in this paper all perform cross-sectional comparative or correlational analyses. The differences in grey matter, for example, between individuals with low versus high ability suggest that increases in grey matter may be caused by the process of skill acquisition. The influence for this perspective comes from other studies reported in the neuroimaging literature outside the domain of language, where increases in grey matter density have been shown to correlate within subjects with task performance such as juggling (Draganski et al. 2004; Boyke et al. 2008), and where decreases in grey matter also occur in the same region once this skill ceases to be practiced. However, this is one of two potential explanations for structural brain differences in cross-sectional studies. An alternative explanation is that higher grey matter values may represent increased neural resources that are a necessary precursor to learning, facilitating the acquisition of a given skill. A causal link between learning and change in local brain structure can only be established through the use of longitudinal studies. Therefore, there is a need for studies of this type in the language arena in order to determine whether improvements in language skills are caused by increases in grey matter within the same individuals, or whether some individuals have higher grey matter in some brain regions which enables them to attain higher levels of language proficiency.

An interesting feature of many structural imaging studies reviewed in this paper, is the demonstration of a clear relationship between local brain structure, language skills, and functional activation. For instance, a region with increased grey matter can show a corresponding increase in functional activation (as illustrated in Fig. 2). This type of correspondence between structure and function suggests that variation in local brain structure and functional activation may be influenced by a common underlying mechanism. The identification of this relationship between structure and function reinforces this close relationship. However, the mechanisms by which such corresponding changes occur are yet to be understood. 
Fig. 4 DTI studies that correlate reading ability with FA. Locations of the peak co-ordinates from the following studies: red Klingberg et al. (2000), yellow Beaulieu et al. (2005), blue Deutsch et al. (2005), green Niogi and McCandliss (2006), and pink Steinbrink et al. (2008). (For figure co-ordinates see Table 5 in Appendix)

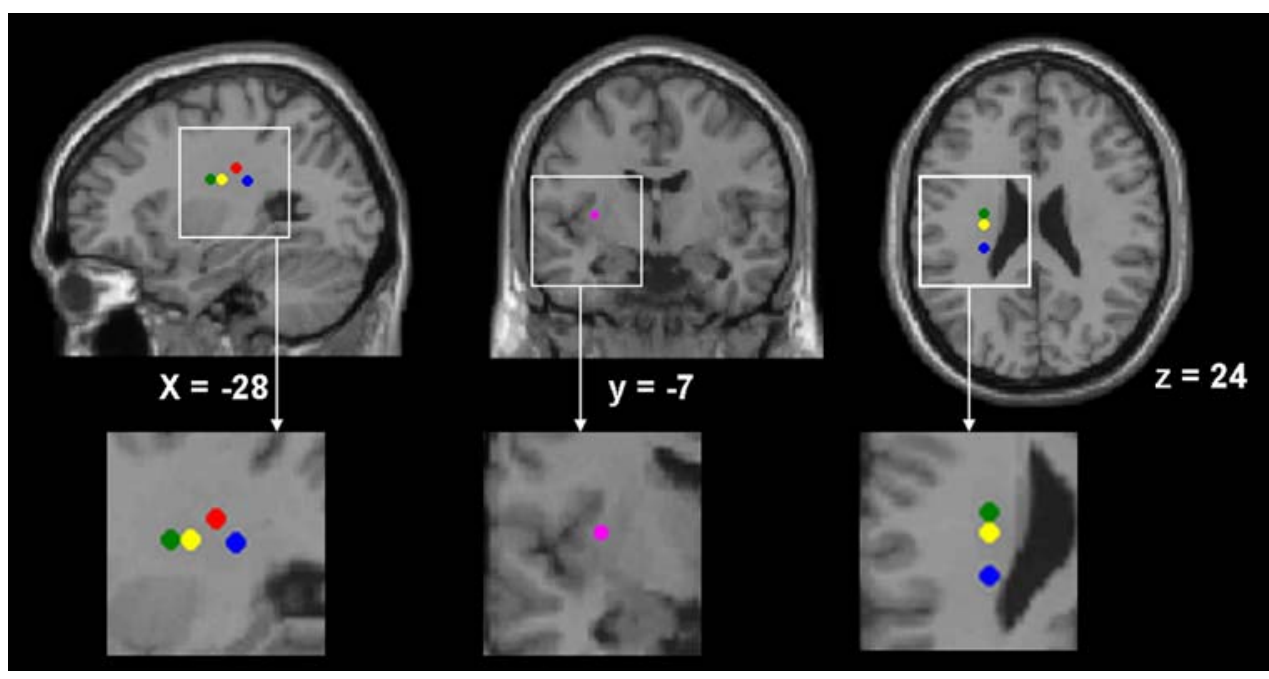

The pattern of difference established in structural studies of language in the typical population is that a higher quantity of the neural substrate being measured represents better performance on a given task. This basic rule of thumb is, to a certain extent, consistent across acquired and developmental disorders of language. For instance, acquired disorders link the absence of particular brain regions with linguistic deficits, while developmental disorders of language, such as dyslexia, associate lower grey matter (as shown in Fig. 3) or FA values (as shown in Fig. 4) with poorer performance on reading and phonological processing tasks (Beaulieu et al. 2005; Deutsch et al. 2005; Klingberg et al. 2000; Kronbichler et al. 2008; Niogi and McCandliss 2006; Silani et al. 2005; Steinbrink et al. 2008; Vinckenbosch et al. 2005). In this context, broad parallels can be drawn with functional studies that associate hypo-activation during similar tasks with poorer performance (Backes et al. 2002; Brambati et al. 2006; Hoeft et al. 2007; Paulesu et al. 2001; Shaywitz and Shaywitz 2005; Shaywitz et al. 2002, 2003).

Another important point to note about regional correlations between brain structure and ability is that they may not always be consistently detected across lifespan (Richardson et al. 2009). Thus, different language acquisition mechanisms may be active at different points of development. Again, this is a particularly relevant point within the context of developmental disorders, since the trajectory of development for the acquisition of language skills deviates from that of typical individuals (Karmiloff-Smith 1998). For example, children with dyslexia may rely on atypical mechanisms to acquire language skills thereby presenting a different pattern of brain structure across regions in comparison to normal development. In this instance, establishing patterns of change over time in brain structure associated with changes in behavioural performance on a range of different language tasks will be particularly important in deciphering the process of language acquisition. In turn, this process will also identify those abnormalities which are most consistently associated with the disorder across different age groups.

In conclusion, in the short history of structural imaging of behavioural skills, studies have evolved to combine structural and functional imaging approaches within the same group of participants. This is perhaps the most powerful use of methodology in order to understand the relationship between brain structure, activation and behaviour. In years to come we anticipate that this integrated approach will provide further significant advances in our understanding of how the brain processes language.

Open Access This article is distributed under the terms of the Creative Commons Attribution Noncommercial License which permits any noncommercial use, distribution, and reproduction in any medium, provided the original author(s) and source are credited.

\section{Appendix}

The co-ordinates for Figs. 1, 3, and 4 are given in the following Tables 3, 4, and 5 .

Table 3 Co-ordinates for Fig. 1

\begin{tabular}{lrll}
\hline Study & \multicolumn{1}{l}{$x$} & $y$ & $z$ \\
\hline 1. Mechelli et al. (2004) & -45 & -59 & 48 \\
& 56 & -53 & 42 \\
2. Lee et al. (2007) & -44 & -54 & 46 \\
& 54 & -50 & 44 \\
3. Richardson et al. (2009) & -40 & -54 & 52 \\
& 48 & -54 & 48 \\
\hline
\end{tabular}

The co-ordinates in this table are in MNI space as reported in the original studies 
Table 4 Co-ordinates for Fig. 3

\begin{tabular}{|c|c|c|c|c|c|c|c|c|c|}
\hline \multirow[t]{2}{*}{ Study } & \multicolumn{3}{|c|}{$\begin{array}{l}\text { (a) Less grey } \\
\text { matter }\end{array}$} & \multicolumn{3}{|c|}{$\begin{array}{l}\text { (b) more grey } \\
\text { matter }\end{array}$} & \multicolumn{3}{|c|}{$\begin{array}{l}\text { (c) behavioural } \\
\text { correlations }\end{array}$} \\
\hline & $x$ & $y$ & $z$ & $x$ & $y$ & $z$ & $x$ & $y$ & $z$ \\
\hline \multirow[t]{7}{*}{ 1. Brown et al. $(2001)^{\mathrm{a}}$} & -57 & -57 & 19 & & & & & & \\
\hline & 18 & -74 & -50 & & & & & & \\
\hline & -32 & 29 & -13 & & & & & & \\
\hline & -30 & -16 & 25 & & & & & & \\
\hline & 0 & -99 & -10 & & & & & & \\
\hline & -12 & 27 & -8 & & & & & & \\
\hline & 0 & 68 & 12 & & & & & & \\
\hline \multirow[t]{9}{*}{ Brambati et al. (2004) ${ }^{\mathrm{a}}$} & 36 & -23 & 18 & & & & & & \\
\hline & -27 & -32 & 12 & & & & & & \\
\hline & 38 & -31 & 26 & & & & & & \\
\hline & -47 & -18 & -31 & & & & & & \\
\hline & -48 & -14 & -17 & & & & & & \\
\hline & -41 & -57 & 12 & & & & & & \\
\hline & 43 & -46 & 1 & & & & & & \\
\hline & 16 & -48 & 34 & & & & & & \\
\hline & -22 & -46 & -40 & & & & & & \\
\hline Silani et al. $(2005)^{\mathrm{a}}$ & -57 & -52 & 2 & -59 & -59 & 6 & -58 & -63 & -15 \\
\hline \multirow[t]{5}{*}{ Vinckenbosch et al. (2005) ${ }^{\mathrm{a}}$} & -62 & -39 & -14 & 16 & -22 & 72 & -32 & 44 & -17 \\
\hline & & & & & & & 24 & 64 & -14 \\
\hline & & & & & & & 38 & 52 & -14 \\
\hline & & & & & & & 64 & -8 & 0 \\
\hline & & & & & & & -70 & -12 & -19 \\
\hline \multirow[t]{5}{*}{ Eckert et al. (2005) } & 12 & -68 & -1 & & & & & & \\
\hline & -14 & -67 & -5 & & & & & & \\
\hline & -39 & -73 & -50 & & & & & & \\
\hline & -55 & -51 & 49 & & & & & & \\
\hline & -23 & 11 & -2 & & & & & & \\
\hline \multirow[t]{6}{*}{ Hoeft et al. $(2007)^{\mathrm{a}}$} & -65 & -30 & 32 & & & & & & \\
\hline & -41 & -4 & 22 & & & & & & \\
\hline & -21 & 0 & 23 & & & & & & \\
\hline & 68 & -23 & 16 & & & & & & \\
\hline & 59 & -37 & 19 & & & & & & \\
\hline & 41 & 11 & 18 & & & & & & \\
\hline \multirow[t]{11}{*}{ Kronbichler et al. (2008) } & 27 & -54 & -33 & 14 & -46 & 44 & 27 & -54 & -33 \\
\hline & 46 & -46 & -33 & -50 & -26 & 3 & 46 & -46 & -33 \\
\hline & -34 & -41 & -31 & 17 & -38 & 60 & -34 & -41 & -31 \\
\hline & -28 & -51 & -30 & 56 & 0 & 23 & -28 & -51 & -30 \\
\hline & 35 & -64 & -8 & 20 & 11 & 51 & 35 & -64 & -8 \\
\hline & 33 & -53 & -19 & 6 & 12 & 54 & 33 & -53 & -19 \\
\hline & -30 & -58 & -6 & -6 & 50 & 18 & -30 & -58 & -6 \\
\hline & -38 & -67 & -15 & 12 & 51 & 5 & -38 & -67 & -15 \\
\hline & 48 & -40 & 27 & & & & 48 & -40 & 27 \\
\hline & -30 & -61 & 33 & & & & & & \\
\hline & 40 & -57 & 6 & & & & & & \\
\hline \multirow[t]{2}{*}{ Steinbrink et al. (2008) } & -56 & -65 & -9 & & & & & & \\
\hline & 61 & -38 & 10 & & & & & & \\
\hline
\end{tabular}


Table 4 continued

\begin{tabular}{|c|c|c|c|c|c|c|c|c|c|}
\hline \multirow[t]{2}{*}{ Study } & \multicolumn{3}{|c|}{$\begin{array}{l}\text { (a) Less grey } \\
\text { matter }\end{array}$} & \multicolumn{3}{|c|}{$\begin{array}{l}\text { (b) more grey } \\
\text { matter }\end{array}$} & \multicolumn{3}{|c|}{$\begin{array}{l}\text { (c) behavioural } \\
\text { correlations }\end{array}$} \\
\hline & $x$ & $y$ & $z$ & $x$ & $y$ & $z$ & $x$ & $y$ & $z$ \\
\hline \multirow{11}{*}{$\begin{array}{l}\text { Pernet et al. (2009) co-ordinates for positive } \\
\text { correlations consistent across groups only }\end{array}$} & & & & & & & -26 & 42 & -14 \\
\hline & & & & & & & -40 & 28 & -4 \\
\hline & & & & & & & -64 & -20 & 4 \\
\hline & & & & & & & -54 & 18 & 6 \\
\hline & & & & & & & 8 & -64 & 10 \\
\hline & & & & & & & -10 & -40 & 48 \\
\hline & & & & & & & -6 & -58 & 50 \\
\hline & & & & & & & -14 & -6 & 72 \\
\hline & & & & & & & 10 & -40 & 52 \\
\hline & & & & & & & 30 & 40 & -14 \\
\hline & & & & & & & 42 & -68 & 38 \\
\hline
\end{tabular}

${ }^{a}$ Co-ordinates for these studies were originally reported in Talairach space. These co-ordinates have been converted into MNI space

Table 5 Co-ordinates for Fig. 4

\begin{tabular}{|c|c|c|c|}
\hline Study & $x$ & $y$ & $z$ \\
\hline 1. Klingberg et al. $(2000)^{a}$ & -28 & -22 & 29 \\
\hline 2. Beaulieu et al. (2005) & -28 & -14 & 24 \\
\hline 3. Deutsch et al. $(2005)^{\mathrm{a}}$ & -28 & -28 & 24 \\
\hline 4. Niogi and McCandliss (2006) & -28 & -11 & 24 \\
\hline 5. Steinbrink et al. (2008) & -33 & -7 & 6 \\
\hline
\end{tabular}

${ }^{a}$ Co-ordinates for these studies were originally reported in Talairach space. These co-ordinates have been converted into MNI space

\section{References}

Ashburner J, Friston K (2000) Voxel-based morphometry-the methods. Neuroimage 11:805-821. doi:10.1006/nimg.2000.0582

Backes W, Vuurman E, Wennekes R, Spronk P, Wuisman M, van Engelshoven J, Jolles J (2002) Atypical brain activation of reading processes in children with developmental dyslexia. J Child Neurol 17:867-871. doi:10.1177/08830738020170121601

Beaulieu C, Plewes C, Paulson LA, Roy D, Snook L, Concha L, Phillips L (2005) Imaging brain connectivity in children with diverse reading ability. Neuroimage 25:1266-1271. doi:10.1016/ j.neuroimage.2004.12.053

Boyke J, Driemeyer J, Gaser C, Büchel C, May A (2008) Traininginduced brain structure changes in the elderly. J Neurosci 28(28):7031-7035. doi:10.1523/JNEUROSCI.0742-08.2008

Brambati SM, Termin C, Ruffino M, Stella G, Fazio F, Cappa SF, Perani D (2004) Regional reductions of gray matter volume in familial dyslexia. Neurology 63:742-745

Brambati SM, Termin C, Ruffino M, Danna M, Lanzi G, Stella G et al (2006) Neuropsychological deficits and neural dysfunction in familial dyslexia. Brain Res 1113:174-185. doi:10.1016/j. brainres.2006.06.099

Brown WE, Eliez V, Menon JM, Rumsey CD, White BA, Reiss AL (2001) Preliminary evidence of widespread morphological variations of the brain in dyslexia. Neurology 56:781-783

Castles A, Coltheart M (1993) Varieties of developmental dyslexia. Cognition 47(2):149-180. doi:10.1016/0010-0277(93)90003-E
Catani M, Allin MPG, Husain M, Pugliese L, Mesulam MM, Murray RM, Jones DK (2007) Symmetries in human brain language pathways correlate with verbal recall. Proc Natl Acad Sci USA 104(43):17163-17168. doi:10.1073/pnas.0702116104

Chee MW, Soon CS, Lee HL, Pallier C (2004) Left insula activation: a marker for language attainment in bilinguals. Proc Natl Acad Sci USA 101:15265-15270. doi:10.1073/pnas.0403703101

Ciccarelli O, Catani M, Johansen-Berg H, Clark C, Thompson A (2008) Diffusion-based tractography in neurological disorders: concepts, applications, and future developments. Lancet Neurol 7:715-727. doi:10.1016/S1474-4422(08)70163-7

Cohen MJ, Morgan AM, Vaughn M, Riccio CA, Hall J (1999) Verbal fluency in children: developmental issues and differential validity in distinguishing children with attention-deficit hyperactivity disorder and two subtypes of dyslexia. Arch Clin Neuropsychol 14(5):433-443

Coltheart M, Rastle K, Perry C, Langdon R, Ziegler J (2001) DRC: a dual route cascaded model of visual word recognition and reading aloud. Psychol Rev 108:204-256. doi:10.1037/0033295X.108.1.204

Cornelissen K, Laine M, Renvall K, Saarinen T, Martin N, Salmelin R (2004) Learning new names for new objects: Cortical effects as measured by magnetoenecephalography. Brain Lang 89:617-622

Démonet J-F, Chollet F, Ramsay S, Cardebat D, Nespoulos J-L, Wise $\mathrm{R}$ et al (1992) Anatomy of phonological and semantic processing in normal subjects. Brain 115:1753-1768. doi:10.1093/brain/ 115.6.1753

Desmond JE, Fiez JA (1998) Neuroimaging studies of the cerebellum: language, learning and memory. Trends Cogn Sci 2:355-361. doi:10.1016/S1364-6613(98)01211-X

Deutsch GK, Dougherty RF, Bammer R, Siok WT, Gabrieli JDE, Wandell B (2005) Children's reading performance is correlated with white matter structure measured by diffusion tensor imaging. Cortex 41:354-363. doi:10.1016/S0010-9452(08)70272-7

Devlin JT, Matthews PM, Rushworth MFS (2003) Semantic processing in the left inferior prefrontal cortex: a combined functional magnetic resonance imaging and transcranial magnetic stimulation study. J Cogn Neurosci 15:71-84. doi:10.1162/0898929033 21107837

Dougherty RF, Ben-Shacher M, Deutsch GK, Hernandez A, Fox GR, Wandell BA (2007) Temporal-callosal pathway diffusivity 
predicts phonological skills in children. Proc Natl Acad Sci USA 104(20):8556-8561. doi:10.1073/pnas.0608961104

Draganski B, Gaser C, Busch V, Schuierer G, Bogdahn U, May A (2004) Neuroplasticity: changes in grey matter induced by training. Nature 427:311-312. doi:10.1038/427311a

Dronkers NF, Husted DA, Deutsch G, Taylor MK, Saunders G, Merzenich MM (1999) Lesion site as a predictor of improvement after Fast ForWord treatment in adult aphasic patients. Brain Lang 69(3):450-452

Eckert MA, Leonard CM, Wilke M, Eckert M, Richards T, Richards A et al (2005) Anatomical signatures of dyslexia in children: unique information from manual and voxel based morphometry brain measures. Cortex 41:304-315. doi:10.1016/S0010-9452 (08)70268-5

Elbro C, Nielsen I, Petersen DK (1994) Dyslexia in adults: evidence for deficits in non-word reading and in the phonological representation of lexical items. Ann Dyslexia 44(1):203-226. doi:10.1007/BF02648162

Fabbro F, Pesenti S, Facoetti A, Bonanomi M, Libera L, Lorusso ML (2001) Callosal transfer in different subtypes of developmental dyslexia. Cortex 37(1):65-73. doi:10.1016/S0010-9452(08) 70558-6

Fawcett AJ, Nicolson RI (1995) Persistent deficits in motor skill of children with dyslexia. J Mot Behav 27(3):235-240

Gaser C, Schlaug G (2003) Brain structures differ between musicians and non-musicians. J Neurosci 23:21-24

Golestani N, Zatorre RJ (2009) Individual differences in the acquisition of second language phonology. Brain Lang 109:55-67

Golestani N, Pallier C (2007) Anatomical correlates of foreign speech sound production. Cereb Cortex 17:929-934. doi:10.1093/ cercor/bh1003

Golestani N, Zatorre RJ (2004) Learning new sounds of speech: reallocation of neural substrates. Neuroimage 21:494-506. doi: 10.1016/j.neuroimage.2003.09.071

Golestani N, Paus T, Zatorre RJ (2002) Anatomical correlates of learning novel speech sounds. Neuron 35:997-1010. doi: 10.1016/S0896-6273(02)00862-0

Golestani N, Molko N, Deheane S, Le Bihan D, Pallier C (2007) Brain structure predicts learning of foreign speech sounds. Cereb Cortex 17:575-582. doi:10.1093/cercor/bhk001

Grogan A, Green DW, Ali N, Crinion JT, Price CJ (2009) Structural correlates of semantic and phonemic fluency ability in first and second languages. J Cogn Neurosci (in press)

Hagmann P, Jonasson L, Maeder P, Thiran J-P, Wedeen VJ, Meuli R (2006) Understanding diffusion MR imaging techniques: from scalar diffusion-weighted imaging to diffusion tensor imaging and beyond. Radiographics 26:S205-S223. doi:10.1148/rg. 26 si065510

Ho CS, Chan DW, Chung KK, Lee SH, Tsang SM (2007) In search of subtypes of Chinese developmental dyslexia. J Exp Child Psychol 97(1):61-83. doi:10.1016/j.jecp.2007.01.002

Hoeft F, Meyler A, Hernandez A, Juel C, Taylor-Hill H, Martindale JL et al (2007) Functional and morphometric brain dissociation between dyslexia and reading ability. Proc Natl Acad Sci USA 4(10):4234-4239. doi:10.1073/pnas.0609399104

Ilg R, Wohlschläger AM, Gaser C, Liebau Y, Dauner R, Wöller A et al (2008) Gray matter increase induced by practice correlates with task-specific activation: a combined functional and morphometric magnetic resonance imaging study. J Neurosci 28(16):4210-4215. doi:10.1523/JNEUROSCI.5722-07.2008

Johnson MH (2005) Sensitive periods in functional brain development: problems and prospects. Dev Psychobiol 46:287-292. doi: 10.1002/dev.20057

Karmiloff-Smith A (1998) Development itself is the key to understanding developmental disorders. Trends Cogn Sci 2(10):389398. doi:10.1016/S1364-6613(98)01230-3
Kilian AS, Nagy W, Pearson PD, Anderson RC, García GE (1995) Learning vocabulary from context: effects of focusing attention on individual words during reading. Technical report, Center for the Study of Reading, No. 619

Klingberg T, Hedehus M, Temple E, Salz T, Gabrieli JDE, Moseley ME et al (2000) Microstructure of temporo-parietal white matter as a basis for reading ability: evidence from diffusion tensor magnetic resonance imaging. Neuron 25:493-500. doi:10.1016/ S0896-6273(00)80911-3

Kronbichler M, Wimmer H, Saffen W, Hutzler F, Mair A, Ladurner G (2008) Developmental dyslexia: grey matter abnormalities in the occipitotemporal cortex. Hum Brain Mapp 29:613-625. doi: 10.1002/hbm.20425

Le Bihan D, Mangin J-F, Poon C, Clark CA, Pappata S, Molko N, Hughes C (2001) Diffusion tensor imaging: concepts and applications. J Magn Reson Imaging 13:534-546. doi:10.1002/ jmri.1076

Lee HL, Devlin JT, Shakeshaft C, Stewart LH, Brennan A, Glensman $\mathrm{J}$ et al (2007) Anatomical traces of vocabulary acquisition in the adolescent brain. J Neurosci 27:1184-1189. doi:10.1523/ JNEUROSCI.4442-06.2007

Lenneberg E (1967) Biological foundations of language. Wiley, New York

Lyon GR, Shaywitz SE, Shaywitz BA (2003) A definition of dyslexia. Ann Dyslexia 53:1-14. doi:10.1007/s11881-003-0001-9

Maguire EA, Burgess N, Donnett JG, Frackowiack RSJ, Frith CD, O'Keefe J (1998) Knowing where and getting there: a human navigation network. Science 280:921-924. doi:10.1126/science. 280.5365.921

Maguire EA, Gadian DG, Johnrude IS, Good CS, Ashburner J, Frackowiack RSJ, Frith CD (2000) Navigation-related structural changes in the hippocampi of taxi drivers. Proc Natl Acad Sci USA 97:4398-4403. doi:10.1073/pnas.070039597

Manis FR, Seidenberg MS, Doi LM, McBride-Chang C, Petersen A (1996) On the bases of two subtypes of developmental dyslexia. Cognition 58(2):157-195. doi:10.1016/0010-0277(95)00679-6

Mechelli A, Crinion JT, Noppeney U, O’Doherty J, Ashburner J, Frackowiak RSJ, Price CJ (2004) Neurolinguistics: structural plasticity in the bilingual brain. Nature 431:757. doi:10.1038/ 431757a

Mechelli A, Price CJ, Friston K, Ashburner J (2005) Voxel-based morphometry of the human brain: methods and applications. Curr Med Imaging Rev 1:105-113. doi:10.2174/1573405054038726

Mummery CJ, Patterson K, Hodges JR, Wise RJ (1996) Generating 'tiger' as an animal name or word beginning with T: differences in brain activation. Proc Biol Sci 263:989-995. doi:10.1098/ rspb.1996.0146

Nagy W, Herman PA, Anderson RC (1985) Learning words from context. Read Res Q 20:233-253. doi:10.2307/747758

Niogi SN, McCandliss BD (2006) Left lateralized white matter microstructure accounts for individual differences in reading ability and disability. Neuropsychologia 44:2178-2188. doi: 10.1016/j.neuropsychologia.2006.01.011

Patterson K, Ralph MA (1999) Selective disorders of reading? Curr Opin Neurobiol 9(2):235-239. doi:10.1016/S0959-4388(99) 80033-6

Patterson K, Shewell C (1987) Speak and spell: dissociations and word class effects. In: Coltheart M, Satori G, Job R (eds) Cognitive neuropsychology of language. Erlbaum, London, pp 273-294

Paulesu E, Demonet J-F, Fazio F, McCrory E, Chanoine V, Brunswick N et al (2001) Dyslexia: cultural diversity and biological unity. Science 291:2165-2167. doi:10.1126/science. 1057179

Pernet C, Andersson J, Paulesu E, Demonet JF (2009) When all hypotheses are right: a multifocal account of dyslexia. Human Brain Mapping 30(7):2278-2292 
Plaut DC, McClelland JL, Seidenberg MS, Patterson K (1996) Understanding normal and impaired word reading: computational principles in quasi regular domains. Psychol Rev 103(1):56-115

Price CJ, More CJ, Humphreys GW, Wise RJ (1997) Segregating semantic from phonological processes during reading. J Cogn Neurosci 9:3876-3883. doi:10.1162/jocn.1997.9.6.727

Ramus F (2004) Neurobiology of dyslexia: a reinterpretation of the data. Trends Neurosci 27:721-726. doi:10.1016/j.tins.2004. 10.004

Ramus F, Rosen S, Dakin SC, Day BL, Castelotte JM, White S, Frith U (2003) Theories of developmental dyslexia: insights from a multiple case study of dyslexic adults. Brain 126:841-865. doi: 10.1093/brain/awg076

Richardson FM, Thomas MSC, Filipii R, Harth H, Price CJ (2009) Contrasting effects of vocabulary acquisition on temporal and parietal brain structure across lifespan. J Cogn Neurosci (in press)

Schneider P, Scherg M, Dorsch HG, Specht HJ, Gutschalk A, Rupp A (2002) Morphology of Heschl's gyrus reflects enhanced activation in the auditory cortex of musicians. Nat Neurosci 5:688694. doi: $10.1038 / \mathrm{nn} 871$

Seghier ML, Lee HW, Schofield T, Price CJ (2008) Inter-subject variability in the use of two different neuronal networks for reading aloud familiar words. Neuroimage 42(3):1226-1236. doi:10.1016/j.neuroimage.2008.05.029

Seidenberg MS, McClelland JL (1989) A distributed, developmental model of word recognition and naming. Psychol Rev 96(4):523568. doi:10.1037/0033-295X.96.4.523

Shaywitz SE, Shaywitz BA (2005) Dyslexia (specific reading disability). Biol Psychiatry 57:1301-1309. doi:10.1016/j.biopsych. 2005.01.043

Shaywitz SE, Fletcher JM, Holahan JM, Shneider AE, Marchione KE, Stuebing KK et al (1999) Persistence of dyslexia: the Connecticut longitudinal study of adolescence. Pediatrics 104:13511359. doi:10.1542/peds.104.6.1351

Shaywitz BA, Shaywitz SE, Pugh KE, Fulbright RK, Mencl WE, Fulbright RK et al (2002) Disruption of posterior brain systems for reading in children with developmental dyslexia. Biol Psychiatry 52:101-110. doi:10.1016/S0006-3223(02)01365-3
Shaywitz SE, Shaywitz BA, Fulbright RK, Skudlarski P, Mencl WE, Constable TR et al (2003) Neural systems for compensation and persistence: young adult outcome of childhood reading disability. Biol Psychiatry 54:25-33. doi:10.1016/S0006-3223(02)01836-X

Shu H, Meng X, Chen X, Luan H, Cao F (2005) The subtypes of developmental dyslexia in Chinese: evidence from three cases. Dyslexia 11(4):311-329. doi:10.1002/dys.310

Silani G, Frith U, Demonet J-F, Fazio F, Perani D, Price C et al (2005) Brain abnormalities underlying altered activation in dyslexia: a voxel based morphometry study. Brain 128:2453-2461. doi: 10.1093/brain/awh579

Snowling MJ (2000) Dyslexia, 2nd edn. Blackwell, Oxford

Sprenger-Charolles L, Colé P, Lacert P, Serniclaes W (2000) On subtypes of developmental dyslexia: evidence from processing time and accuracy scores. Can J Exp Psychol 54(2):87-104. doi: $10.1037 / \mathrm{h} 0087332$

Stanovich KE, Siegel LS (1994) Phenotypic performance profile of reading-disabled children: a regression-based test of the phonological core variable-difference model. J Educ Psychol 86:2453. doi:10.1037/0022-0663.86.1.24

Steinbrink C, Vogt K, Kastrup A, Müller H-P, Juengling FD, Kassubek J, Rieker A (2008) The contribution of white and gray matter differences to developmental dyslexia: insights from DTI and VBM at 3.0T. Neuropsychologia 46:3170-3178. doi: 10.1016/j.neuropsychologia.2008.07.015

Vinckenbosch E, Robichon F, Eliez Z (2005) Grey matter alteration in dyslexia: converging evidence from volumetric and voxelby-voxel MRI analyses. Neuropsychologia 43:324-331. doi: 10.1016/j.neuropsychologia.2004.06.023

Wong PC, Warrier CM, Penhune VB, Roy AK, Sadehh A, Parrishs TB, Zatorre RJ (2008) Volume of left Heschl's gyrus and linguistic pitch learning. Cereb Cortex 18:828-836. doi:10.1093/ cercor/bhm 115

Zabell C, Everatt J (2002) Surface and phonological subtypes of adult developmental dyslexia. Dyslexia 8(3):160-177. doi:10.1002/ dys. 223

Ziegler JC, Castel C, Pech-Georgel C, George F, Alario FX, Perry C (2008) Developmental dyslexia and the dual route model of reading: simulating individual differences and subtypes. Cognition 107(1):151-178. doi:10.1016/j.cognition.2007.09.004 